\title{
Traduire
}

Une autre perspective sur r tr traduction

Revue française de la traduction

$216 \mid 2008$

Question de confiance

\section{Prix Pierre-François Caillé de la traduction 2007}

\section{Héloïse Neefs}

\section{(2) OpenEdition \\ Journals}

Édition électronique

URL : http://journals.openedition.org/traduire/988

DOI : 10.4000/traduire.988

ISSN : 2272-9992

\section{Éditeur}

Société française des traducteurs

Édition imprimée

Date de publication : 1 mars 2008

Pagination : 79-80

ISSN : 0395-773X

\section{Référence électronique}

Héloïse Neefs, «Prix Pierre-François Caillé de la traduction 2007 », Traduire [En ligne], 216 | 2008, mis en ligne le 01 mars 2008, consulté le 25 septembre 2020. URL : http://journals.openedition.org/ traduire/988 ; DOI : https://doi.org/10.4000/traduire.988 


\title{
Prix Pierre-François Caillé de la traduction 2007
}

\author{
HÉLOÏSE NEEFS \\ Écholalies. Essai sur l'oubli des langues \\ de Daniel Heller-Roazen \\ traduit de l'anglais par Justine Landau \\ Paris, Seuil, 2007
}

L'écholalie est une pathologie du langage. Celui qui en est affecté répond à ses interlocuteurs en reprenant en écho, automatiquement et systématiquement, les mots qu'ils viennent de prononcer.

Dans son livre Écholalies, Daniel Heller-Roazen donne à l'écholalie un sens linguistique : la langue est faite d'échos, écho des mots, écho des autres langues. Chaque langue est l'écho du babil enfantin (babil de Babel) dont l'effacement a permis la parole. Chaque langue garde la trace de l'oubli d'autres langues.

À travers vingt et un essais, l'auteur explore la mythologie, la théologie, la linguistique, la philosophie, la psychanalyse, la neurologie et s'intéresse à la littérature arabe, aux écrits de Freud sur l'aphasie, aux idiomes sacrés du judaïsme et de l'islam, aux dialectes en voie de disparition, à la langue maternelle, à la naissance du français, à la renaissance de l'hébreu.

Écholalies est une traversée des sciences et des sciences du langage qui exigeait de très grandes compétences scientifiques et linguistiques et une érudition maîtrisée. Justine Landau, la traductrice, a fait ici un travail remarquable, exceptionnel, et collaboré avec l'auteur qui a voulu ajouter certaines choses pour cette publication. On admirera aussi le sérieux de l'appareil critique : notes, bibliographie et index. 
Cette année, le jury du Prix Pierre-François Caillé se réunissait pour primer un ouvrage scientifique, technique ou de vulgarisation. Il a accordé le prix à Justine Landau. Elle a à peine trente ans. Elle est agrégée de lettres modernes et enseigne la littérature persane à l'université Paris III. Cette première traduction montre de formidables qualités de sérieux, de rigueur et d'aisance. Nous souhaitons à Justine Landau les plus grands succès. 